\title{
Perancangan Sistem Informasi Pengolahan Jadwal Mata Pelajaran Siswa Secara Online Di SMPN 31 Padang Berbasis Web
}

\author{
Khairunnisa Samosir ${ }^{1}$, Darmansah ${ }^{2}$, Ni Wayan Wardani ${ }^{3}$ \\ ${ }^{1}$ Universitas Graha Nusantara Padang Sidimpuan, Jl Willem Iskandar, (0634) 25292 \\ ${ }^{2}$ Institut Teknologi Telkom Purwokerto; Jl. DI. Panjaitan No.128 Purwokerto, \\ Telp 0281-641629 \\ ${ }^{3}$ Stmik Stikom Indonesia; Jl. Tukad Pakerisan No. 97 Panjer, Denpasar \\ e-mail: *11ksamosir35@gmail.com, ${ }^{2}$ darmansah@ittelkom-pwt.ac.id, ${ }^{2}$ niwayan.wardani@ stiki- \\ indonesia.ac.id
}

\begin{abstract}
Abstrak
Saat ini penjadwalan pelajaran pada SMP NEGERI 31 Padang masih dilakukan secara manual oleh bagian kurikulum, dengan sebelumnya dilakukan rapat pembagian tugas bersama guru mata pelajaran. Dari penentuan banyaknya kelas, banyaknya guru di sekolah dan banyaknya jam mengajar untuk setiap guru masih dilakukan secara manual. Alokasi dan penentuan guru merupakan elemen yang penting dalam penyusunan jadwal mata pelajaran, namun juga menjadi permasalahan yang umum dalam proses penyusunan jadwal. Dengan membangun Sistem Informasi berbasis web SMP NEGERI 31 Padang mampu memudahkan pengolahan data siswa, guru, dan jadwal mata pelajaran siswa sehingga dapat diperoleh hasil yang cepat, tepat dan akurat.
\end{abstract}

Kata kunci-Sistem Informasi, PHP, MySQL, UML

\begin{abstract}
Currently scheduling lessons at SMP NEGERI 31 Padang is still done manually by the curriculum section, with previously held a task division meeting with subject teachers. From determining the number of classes, the number of teachers in the school and the number of teaching hours for each teacher are still done manually. The allocation and determination of teachers is an important element in the preparation of subject schedules, but is also a common problem in the schedule preparation process. By building a web-based information system SMP NEGERI 31 Padang is able to facilitate data processing of students, teachers, and course schedules so that fast, precise and accurate results can be obtained.
\end{abstract}

Keywords-Information Systems, PHP, MySQL, UML

\section{PENDAHULUAN}

Saat ini merupakan era teknologi informasi global, dimana segala sesuatu dilakukan dengan serba praktis, tepat dan terbaru dengan informasi yang diperoleh dari manapun dan kapanpun [1]. Eknologi informasi berperan penting dalam memperbaiki kualitas informasi dalam suatu instansi. Penggunaannya tidak hanya sebagai proses otomatisasi terhadap akses informasi, tetapi juga menciptakan ketepatan dan kelengkapan sebuah sistem informasi [2]. Penelitian lainnya mengatakan dengan adanya perkembangan teknologi ini setiap pekerjaan akan dapat direalisasikan secara lebih efisien dan efektif. Sebelum adanya komputer, dalam 
menjalankan aktifitas terasa begitu lamban dan membutuhkan banyak waktu. Dengan adanya teknologi komputer, dapat mempercepat segala aktivitas yang akan dilakukan dengan waktu yang lebih singkat [3]. Penjadwalan mata pelajaran merupakan suatu kegiatan untuk mengalokasikan pelajaran pada blok waktu tertentu dengan memperhatikan batasan-batasan yang ada [4]. saat ini penjadwalan pelajaran pada SMP NEGERI 31 Padang masih dilakukan secara manual oleh bagian kurikulum, dengan sebelumnya dilakukan rapat pembagian tugas bersama guru mata pelajaran. Dari penentuan banyaknya kelas, banyaknya guru di sekolah, dan banyaknya jam mengajar untuk setiap guru masih dilakukan secara manual. Alokasi dan penentuan guru merupakan elemen yang penting dalam penyusunan jadwal mata pelajaran, namun juga menjadi permasalahan yang umum dalam proses penyusunan jadwal. Dengan terbatasnya guru mata pelajaran yang ada, penyusunan jadwal dituntut untuk tetap bisa memenuhi kebutuhan sesuai dengan kelas yang bersedia. Atau bahkan sebaliknya, dengan banyaknya guru yang ada, penyusun jadwal dituntut untuk memenuhi kebutuhan jam mengajar bagi guru yang ada, karena beberapa guru mungkin sudah sertifikasi yang menuntut seorang guru harus memiliki jam mengajar minimal 24 jam pelajaran. Sistem Informasi Sekolah ini, dapat meningkatkan efektifitas dan kinerja sekolah. Karena dengan adanya sistem informasi ini dapat membantu seseorang yang membutuhkan informasi tentang suatu sekolah dapat langsung mengetahuinya tanpa perlu membuang tenaga, waktu, dan biaya untuk datang ke tempat dimana informasi tersebut berada [5]. Dengan membangun Sistem Informasi berbasis web dengan PHP dan MySQ1 diharapkan mampu memudahkan pengolahan data siswa, guru, dan jadwal mata pelajaran siswa sehingga dapat diperoleh hasil yang cepat, tepat dan akurat pada SMP NEGERI 31 Padang.

\subsection{Sistem}

\section{LANDASAN TEORI}

Seperti telah kita diketahui bersama bahwa dewasa ini begitu banyak para ahli mendefinisikan mengenai sistem. Beberapa pengertian sistem yang diambil dalam penelitian kali ini adalah pengertian yang diberikan oleh Sutabri. Sutabri memberikan pengertian sistem sebagai sekelompok unsur-unsur yang erat hubungannya satu dengan yang lain, yang berfungsi bersama-sama untuk mencapai tujuan tertentu (Sutabri, 2012). Dalam arti yang lain, sistem didefinisikan sebagai suatu kumpulan atau himpunan dari unsur, komponen, atau variabel yang terorganisir, saling interaksi, saling tergantung satu sama lain, dan terpadu (Mudjahidin \& Putra, 2010) [6]. Menurut Hanif Al Fatta (2007:3-4), Secara sederhana sistem dapat diartikan sebagai suatu kumpulan atau himpunan dari unsur atau variabel-variabel yang saling terorganisasi. Saling berinteraksi, dan saling bergantung sama lain, adapun gambarannya seperti yang terlihat dibawah ini.

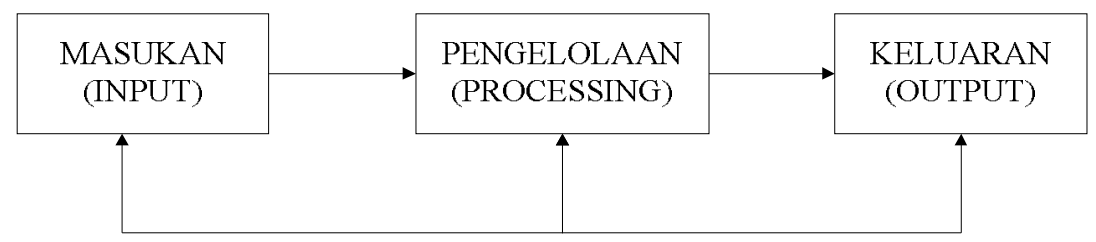

Gambar 1. Model Sistem

Gambar diatas menunjukkan bahwa sistem atau pendekatan sistem minimal harus mempunyai empat komponen, yakni masukan, pengolahan, keluaran, dan balikan atau control [7].

Samosir, et al., [Perancangan Sistem Informasi Pengolahan Jadwal Mata Pelajaran Siswa Secara Online Di SMPN 31 Padang Berbasis Web] 


\subsection{Informasi}

Telah banyak tokoh mendefinisikan informasi. Salah satu diantaranya dikemukakan oleh Jogiyanto. Adapun pengertian yang dikemukakan oleh Jogiyanto adalah kumpulan data yang relevan dan mempunyai arti yang menggambarkan suatu kejadian-kejadian atau kegiatankegiatan (Jogiyanto, 2005). Sutabri mendefinisikan informasi sebagai data yang telah diklasifikasi atau diinterpretasi untuk digunakan dalam proses pengambilan keputusan (Sutabri, 2012) [6]. Penelitian lainnya mengatakan bahwa Informasi merupakan sebuah hasil dari sebuah pengolahan data yang melalui sekumpulan proses pada sebuah sistem, yang diolah sedemikian rupa sehingga layak untuk disajikan kepada masyarakat umum [8].

\subsection{Sistem Informasi}

Sistem informasi adalah sejumlah komponen (manusia, komputer, teknologi informasi, dan prosedur kerja), ada sesuatu yang diproses (data menjadi informasi), dan dimaksudkan untuk mencapai suatu sasaran atau tujuan (Kadir, 2008: 10). Menurut Ladjamudin (2009:13), Sistem Informasi adalah suatu sistem didalam suatu organisasi yang mempertemukan kebutuhan pengolahan transaksi harian, mendukung operasi, bersifat manejerial dan kegiatan strategi dari suatu organisasi dan menyediakan pihak luar tertentu dengan laporan-laporan yang diperlukan (Raymond, McLeod Jr, 2001) [9].

\subsection{UML (Unified Modelling Language)}

UML (Unified Modelling Language) menurut Martin (2005) adalah sebuah "bahasa" yang telah menjadi standar dalam industri untuk visualisasi, merancang, dan mendokumentasikan sistem piranti lunak. UML menawarkan sebuah standar untuk merancang model sebuah sistem [10]. Pendapat lainnya mengatakan bahwa UML (Unified Modeling Language) adalah standar bahasa yang banyak digunakan di dunia industri untuk mendefenisikan requirement, membuat analisis \& desain, serta menggambarkan arsitektur dalam pemograman berorientasi objek [11]. Adapun diagram diagram yang ada dalam UML (Unified Modelling Language) antara lainnya seperti berikut ini.

\section{METODE PENELITIAN}

Metode penelitian yang lakukan dalam mengumpulkan data-data yang ada kaitannya dengan permasalahan di atas adalah:

\subsection{Penelitian Lapangan (Field Research)}

Dalam melakukan penelitian ini langsung ke lapangan yaitu SMP NEGERI 31 Padang untuk mengumpulkan data secara langsung melalui wawancara terhadap pihak yang terkait. Penelitian lapangan ini dilakukan untuk memperoleh gambaran yang lengkap tentang lingkup masalah dan langkah yang tepat dalam pemecahannya serta membuat penelitian ini menjadi lebih terarah dan tidak mengambang.

\subsection{Penelitian Perpustakaan (Library Reseach)}

Penelitian yang di lakukan untuk mendapatkan data sekunder dengan membaca buku, jurnal, literatur-literatur yang berhubungan dengan judul penelitian, menyusun teori-teori yang berhubungan dengan pembahasan sehingga terjadi perpaduan yang kompleks yang satu dengan yang lainnya.

Samosir, et al., [Perancangan Sistem Informasi Pengolahan Jadwal Mata Pelajaran Siswa Secara Online Di SMPN 31 Padang Berbasis Web] 


\subsection{Penelitian Laboratorium (Laboratory Research)}

Dalam hal ini tidak menggunakan alat perangkat labor tetapi menggunakan perangkat Hardware Software sendiri dengan spesifikasi terdiri dari:

\subsubsection{Hardware}

1) Processor Intel(R) Core(TM) i3-2328 CPU @ 2.20GHz $2.20 \mathrm{GHz}$

2) Memory(RAM) 2,00 GB

3) Harddisk $500 \mathrm{~GB}$

4) Flashdisk Sony $16 \mathrm{~Gb}$

5) Printer Canon Pixma MP287

\subsubsection{Software}

1) Sistem Operasi Windows 7 Ultimate

2) Microsoft Office 2007

3) Notepad++

4) Software XAMPP

5) Macromedia Dreamweaver 8

6) Serta software pendukung lainnya.

\subsection{Pengujian Sistem}

Pengujian sistem dilakukan pada penelitian ini menggunakan pengujian antarmuka dengn model behavior yaitu use case diagram, Activity Diagram, Sequence Diagram dan Class Diagram. Pengujian ini memastikan bahwa informasi masukan (input) dan keluaran (output) dari modul-modul perangkat lunak mengalir dengan benar.

\section{HASIL DAN PEMBAHASAN}

Pembahasan terhadap hasil penelitian dan pengujian yang diperoleh disajikan dalam penerapan sistem supaya dapat dioperasikan. Pada tahap ini dijelaskan mengenai analisis, perancangan sistem dan hasil sebuah sistem.

\subsection{Analisis Sistem Berjalan}

Analisa sistem dilakukan dengan tujuan untuk mengetahui kelemahan-kelemahan yang terjadi pada sistem yang sedang berjalan atau sistem lama, karena dengan dilakukannya analisa sistem yang sedang berjalan akan dapat memberikan kemudahan dalam melakukan perancangan dan pengembangan terhadap sistem yang akan dibangun atau sistem baru, dengan dilakukannya analisa terhadap sistem lama nantinya akan dapat dijadikan sebagai perbandingan, pengkoreksian serta pengembangan dan perancangan kearah sistem yang baru.

\subsection{Analisis Sistem yang Diusulkan}

Sistem yang akan dibangun ini bukan untuk menggantikan sistem yang sedang berjalan namun memanfaatkan peluang dengan membuat sistem baru yang berbasis website. Sistem yang baru tersebut diharapkan dapat lebih meningkatkan kinerja dari sistem yang lama sehingga dapat menjadi salah satu penunjang untuk mencapai tujuan organisasi dan mempunyai nilai guna bagi penggunanya. 


\subsection{Rancangan UML (Unified Modeling Language)}

Dalam pembuatan sistem baru menggunakan UML (Unified Modeling Language) sebagai desain perancangan sistem baru. Adapun rancangan desain sistem baru adalah sebagai berikut:

\subsubsection{Use Case Diagram}

Sasaran pemodelan Use Case diantaranya adalah mendefinisikan kebutuhan fungsional dan operasional sistem dengan mendefinisikan scenario penggunaan yang disepakati antara pemakai (user) dan pengembang (admin). Spesifikasi kebutuhan dasar aktor, dalam sistem ini aktor terdiri dari admin, guru, dan siswa.

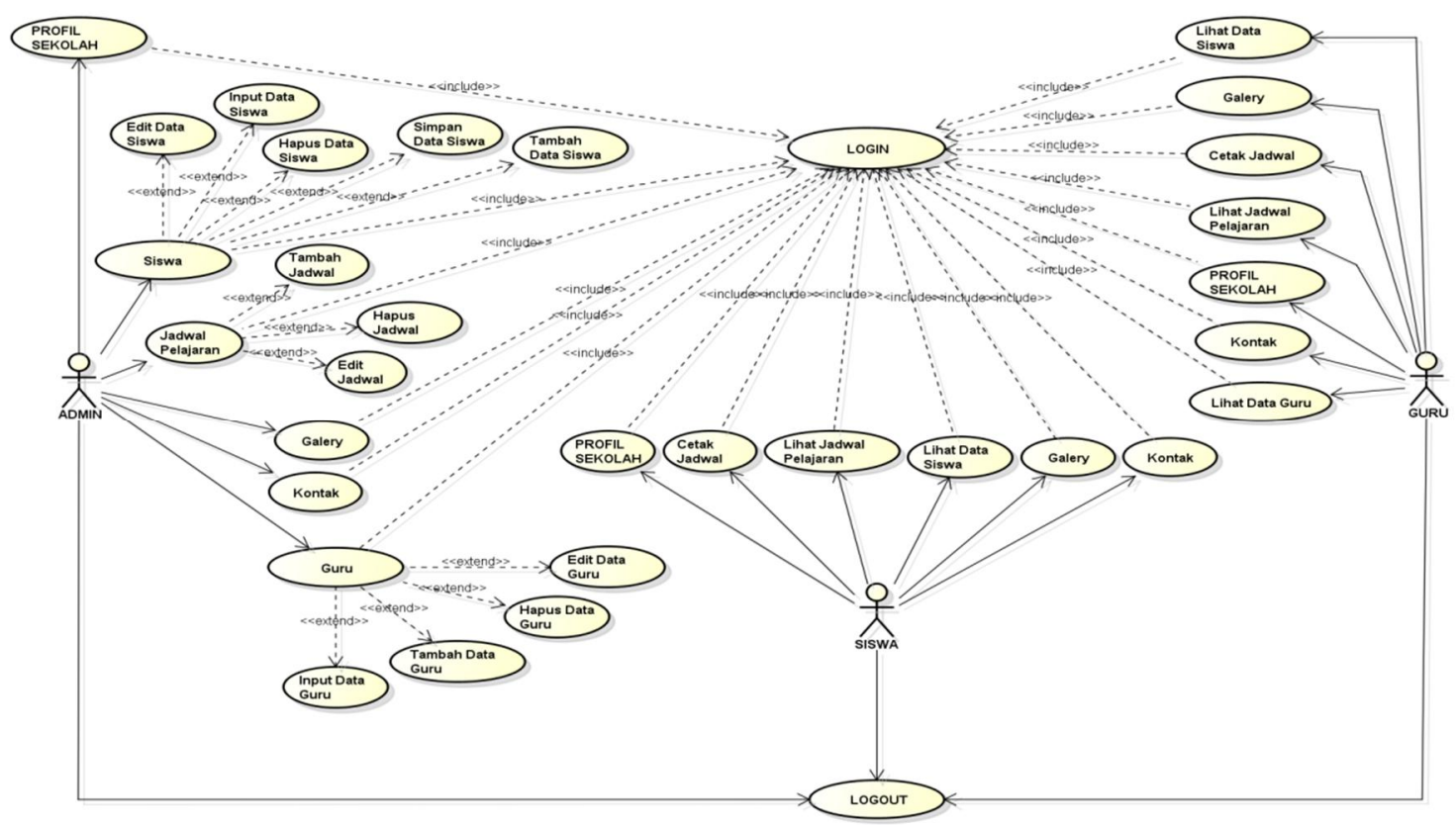

Gambar 2. Use Case Diagram

Gambaran diatas merupakan Use Case Diagram pada sistem jadwal pelajaran. Dalam Use Case Diagram tersebut menggambarkan dimana actor harus memiliki aplikasi Jadwal Pelajaran ini juga harus Login agar bisa melakukan pengolahan sistem. Admin memiliki fasilitas Admin lengkap dalam pengolahan seperti tambah, edit, hapus setiap masalah Jadwal terhadap sistem dan memberikan solusi.

\subsubsection{Activity Diagram}

Activity diagram menggambarkan berbagai aktivitas yang terjadi dalam sistem yang sedang dirancang, bagaimana masing-masing aktifitas berawal, decision yang mungkin terjadi, dan bagaimana sistem berakhir. Activity diagram juga dapat menggambarkan proses paralel yang mungkin terjadi pada beberapa eksekusi. 


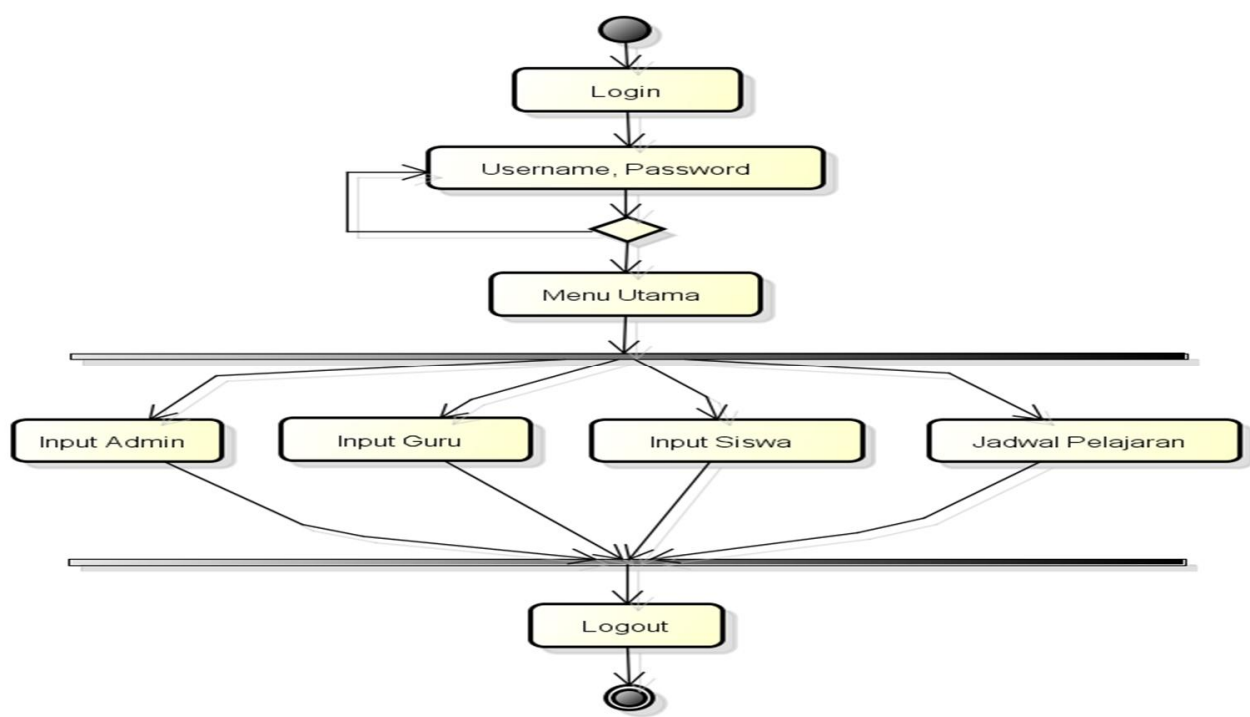

Gambar 3. Activity Diagram Admin

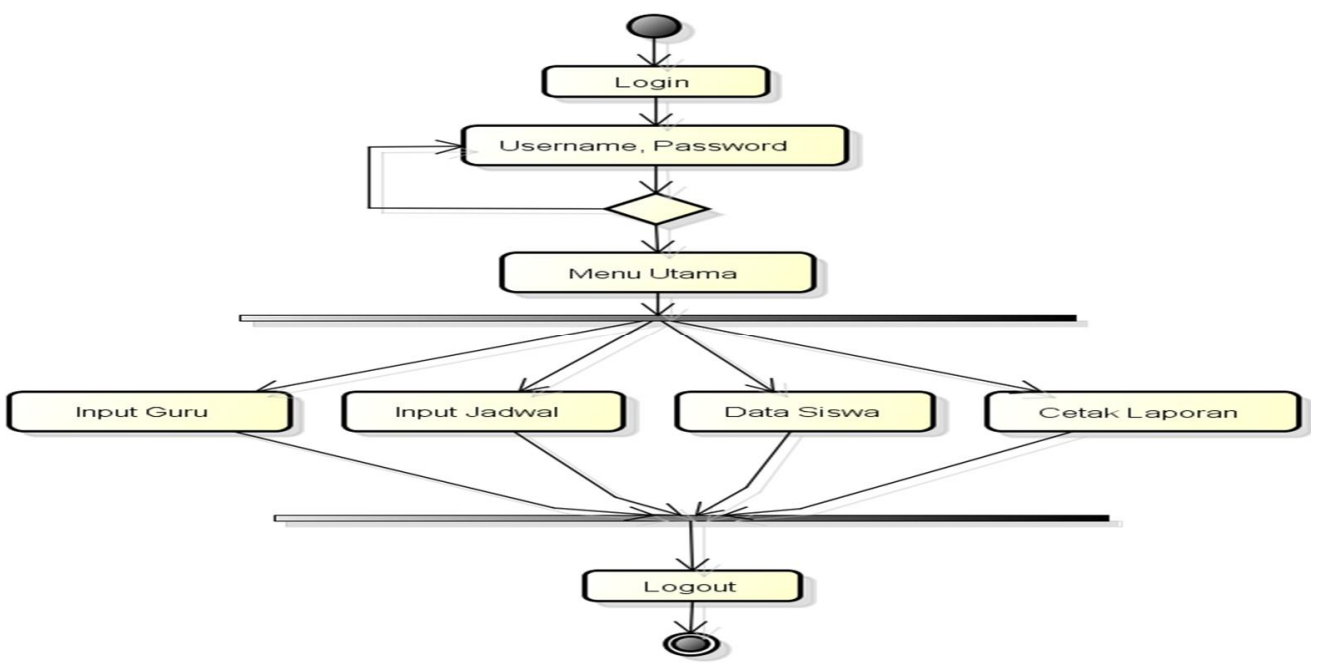

Gambar 4. Activity Diagram Guru

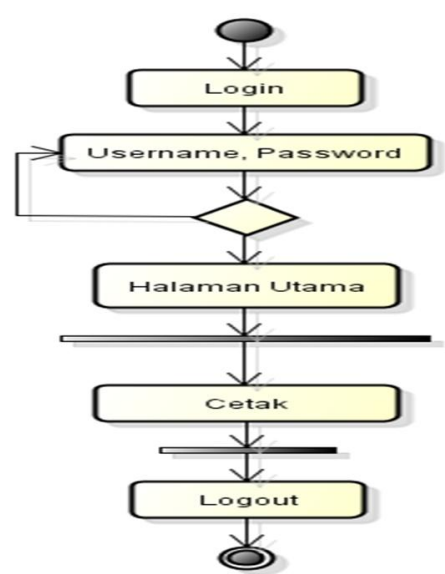

Gambar 5. Activity Diagram Siswa 


\subsubsection{Sequence Diagram}

Sequence diagram menggambarkan interaksi antar objek dalam dan sekitar sistem berupa pesan yang digambarkan terhadap waktu. Biasa menggambarkan skenario atau rangkaian langkah-langkah yang dilakukan sebagai respon dari sebuah event untuk menghasilkan output tertentu.

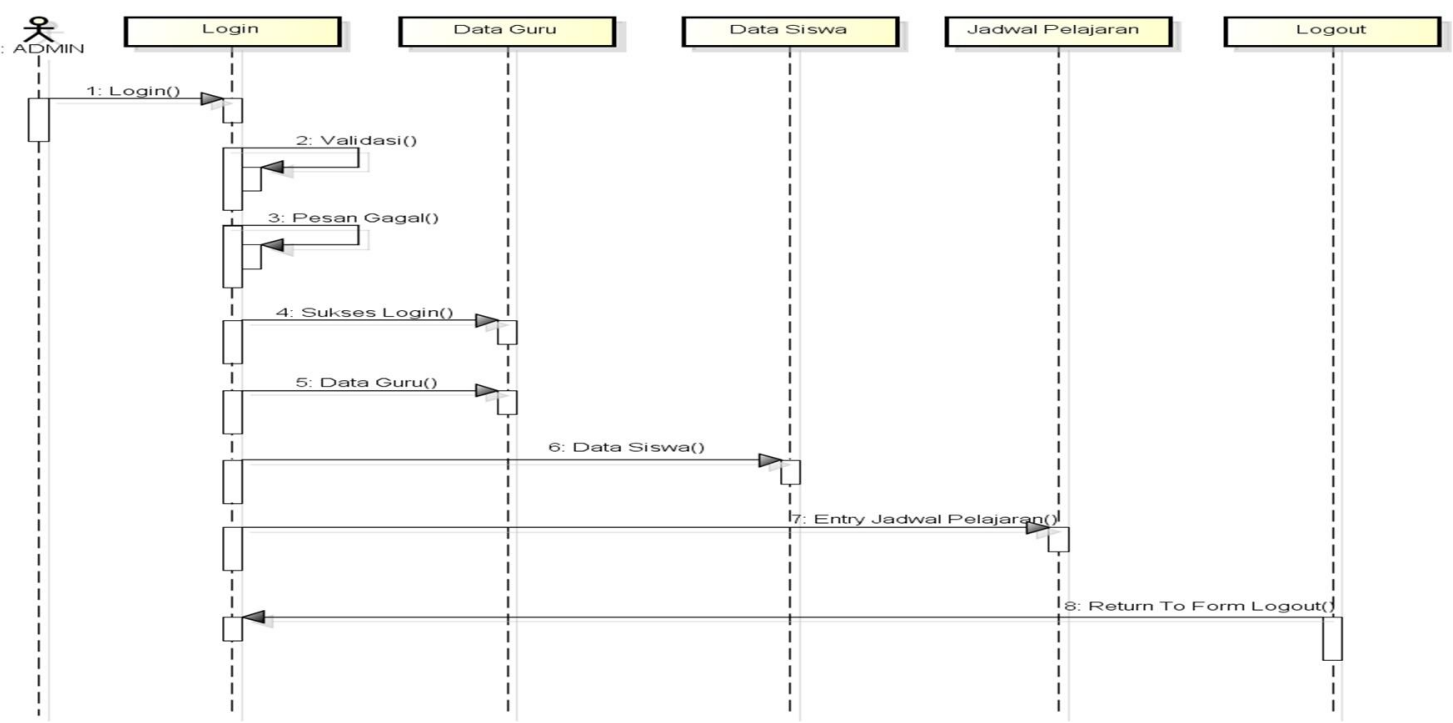

Gambar 6. Sequence Diagram Admin

Sequence Diagram digunakan untuk menggambarkan perilaku pada sebuah Scenario secara detail menurut waktu. Diagram ini menunjukkan sejumlah contoh objek dan message (pesan) yang diletakkan diantara objek-objek didalam Use Case.

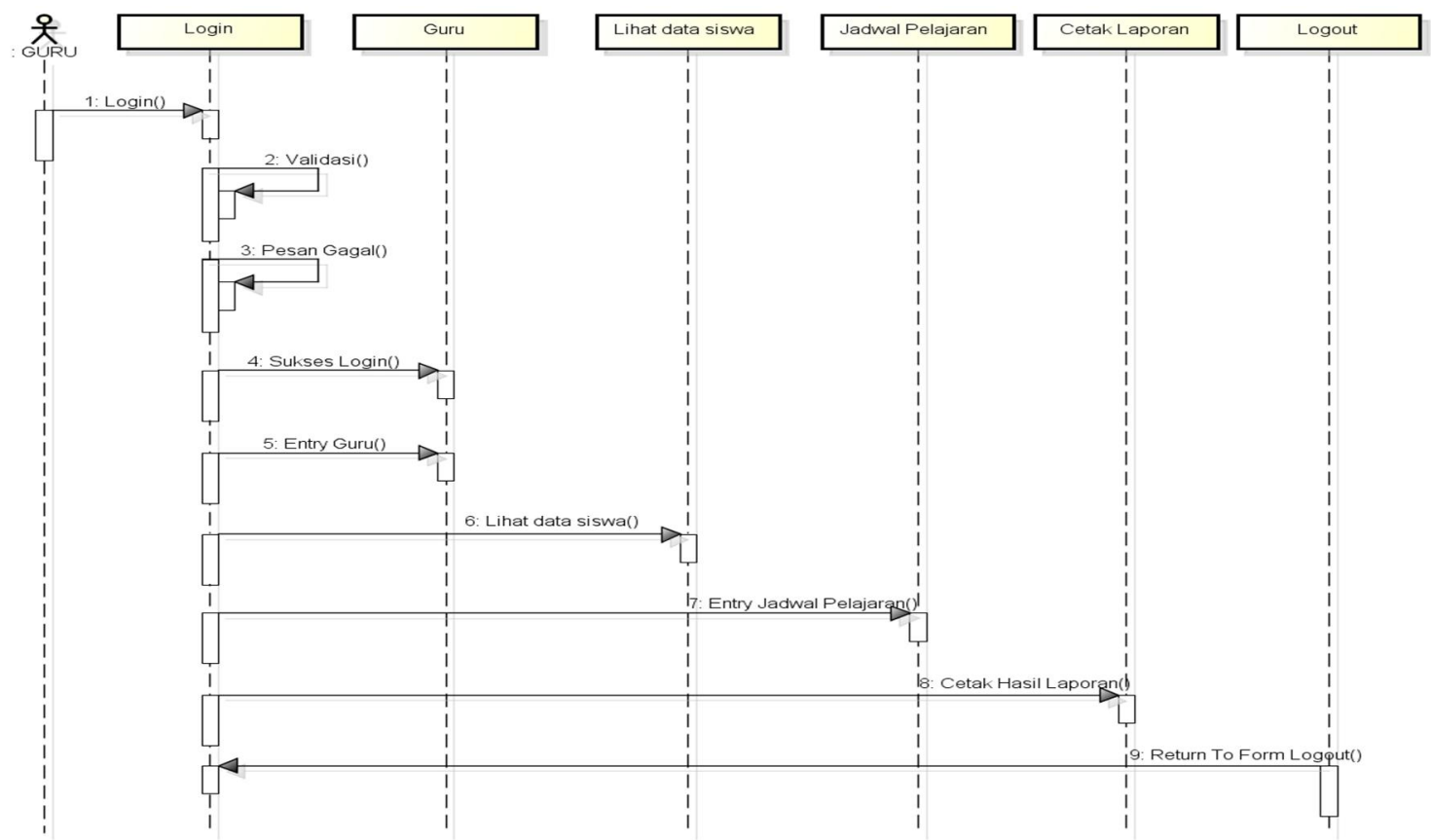

Gambar 7. Sequence Diagram Guru

Samosir, et al., [Perancangan Sistem Informasi Pengolahan Jadwal Mata Pelajaran Siswa Secara Online Di SMPN 31 Padang Berbasis Web] 


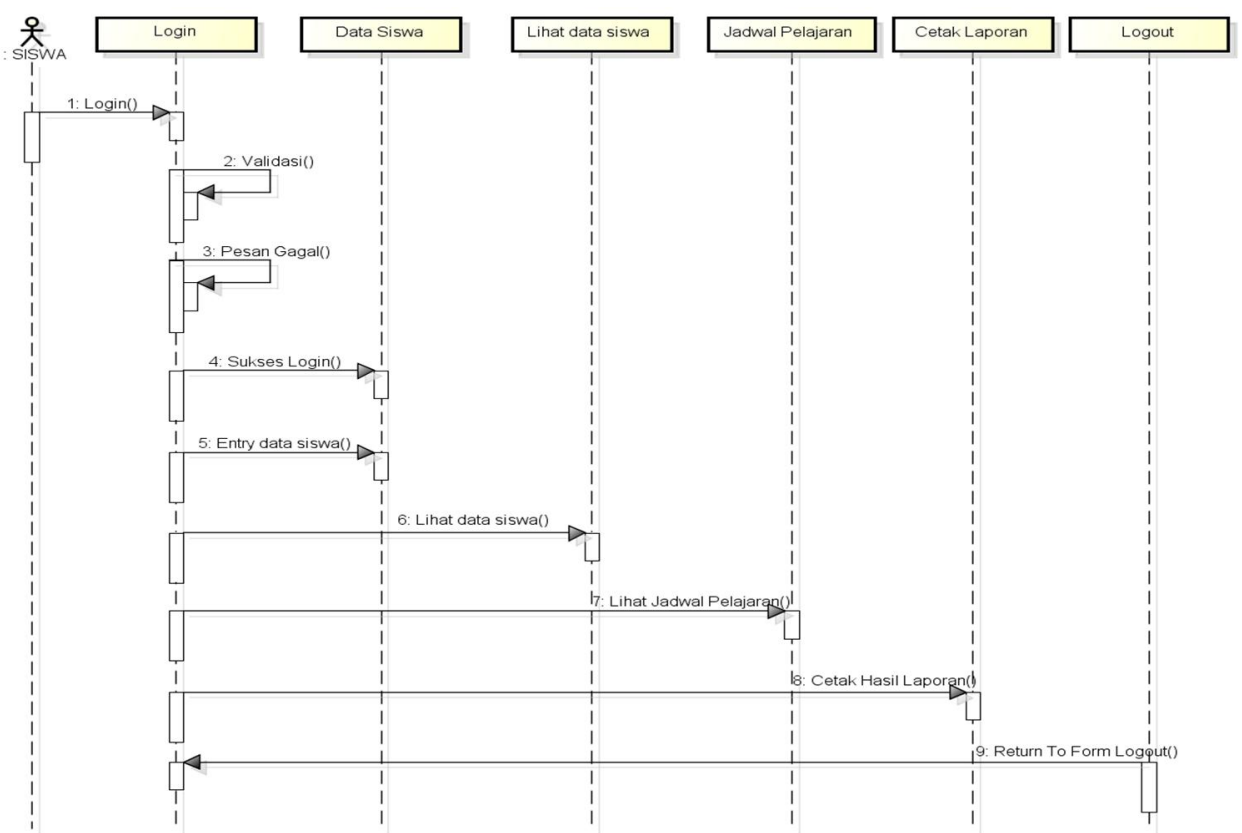

Gambar 8. Sequence Diagram Siswa

\subsubsection{Class Diagram}

Class diagram menampilkan gambaran hubungan antara tabel-tabel yang ada dalam database. Masing-masing class memiliki atribut dan metoda atau fungsi sesuai dengan proses yang terjadi. Class diagram yang terdapat dalam sistem informasi jadwal pelajaran di SMP Negeri 31 Padang sebagai berikut:

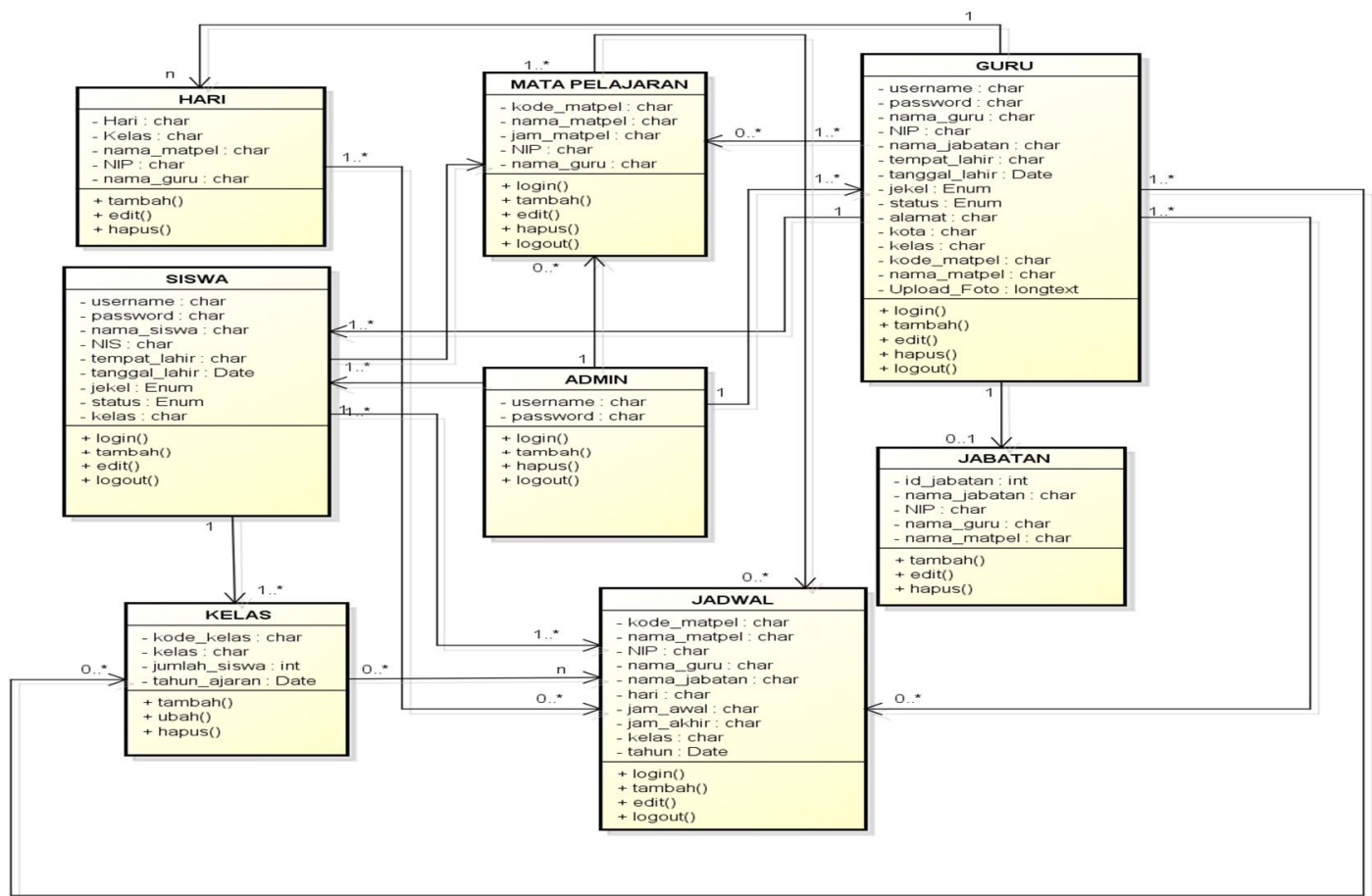

Gambar 9. Class Diagram Siswa

Samosir, et al., [Perancangan Sistem Informasi Pengolahan Jadwal Mata Pelajaran Siswa Secara Online Di SMPN 31 Padang Berbasis Web] 


\subsection{Halaman Login}

Untuk masuk kedalam sebuah website, terlebih dahulu pilih menu login utama pada sistem ini yang dapat diakses oleh kepala sekolah, semua guru, dan siswa. Tampilan menu login website SMP NEGERI 31 Padang dapat dilihat pada gambar di bawah ini:

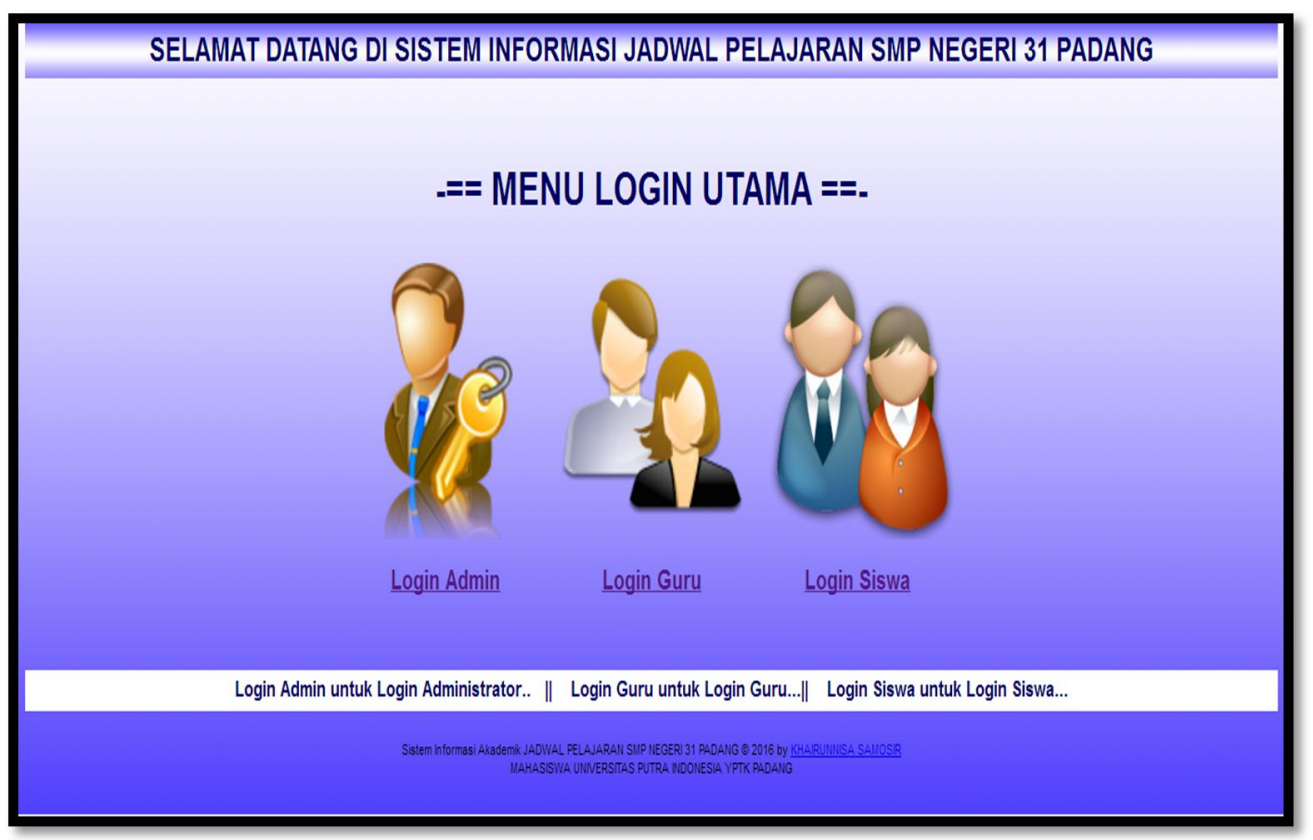

Gambar 10. Menu Login Utama Website

\subsection{Halaman Utama}

Halaman utama pada sistem ini merupakan halaman website yang akan ditampilkan, halaman website ini bisa diakses oleh kepala sekolah, semua guru, dan siswa.

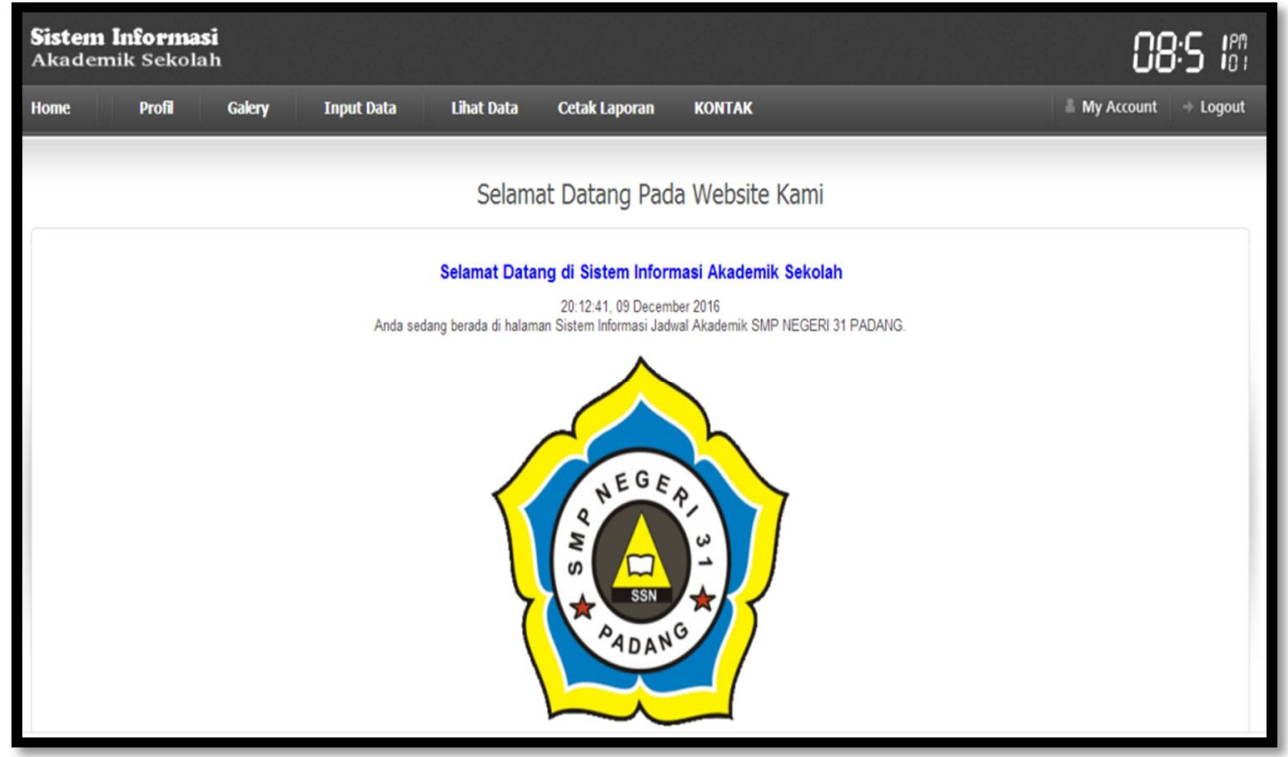

Gambar 11. Halaman Utama 


\subsection{Form Entry Data}

Pada halaman ini akan ditampilkan pendaftaran bagi guru, siswa, jabatan, data kelas, mata pelajaran, jadwal pelajaran. Berikut gambar input data guru tersebut. dapat dilihat pada gambar dibawah ini:

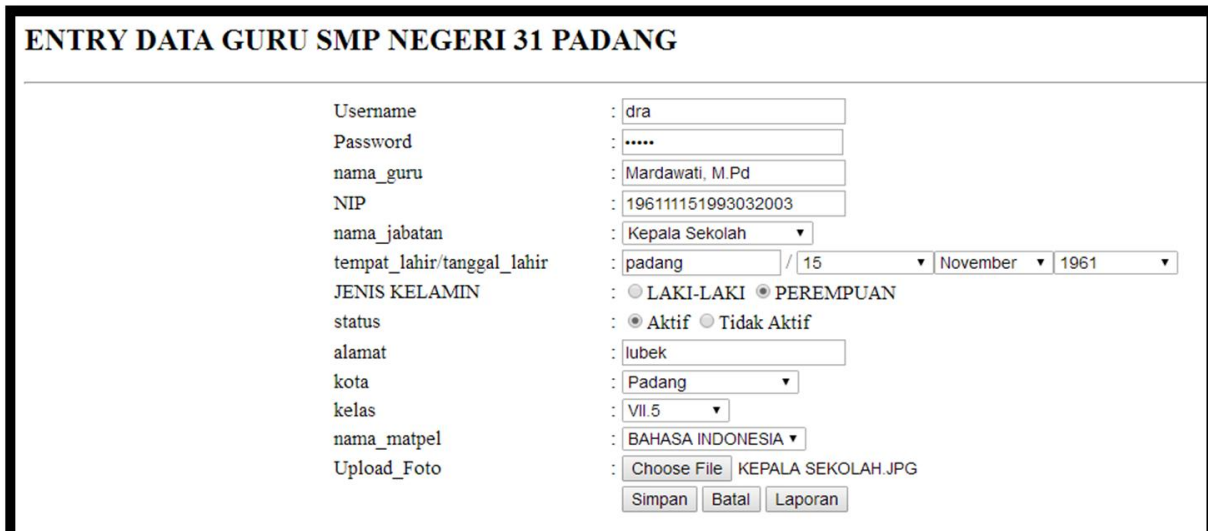

Gambar 12. Tampilan Input Guru

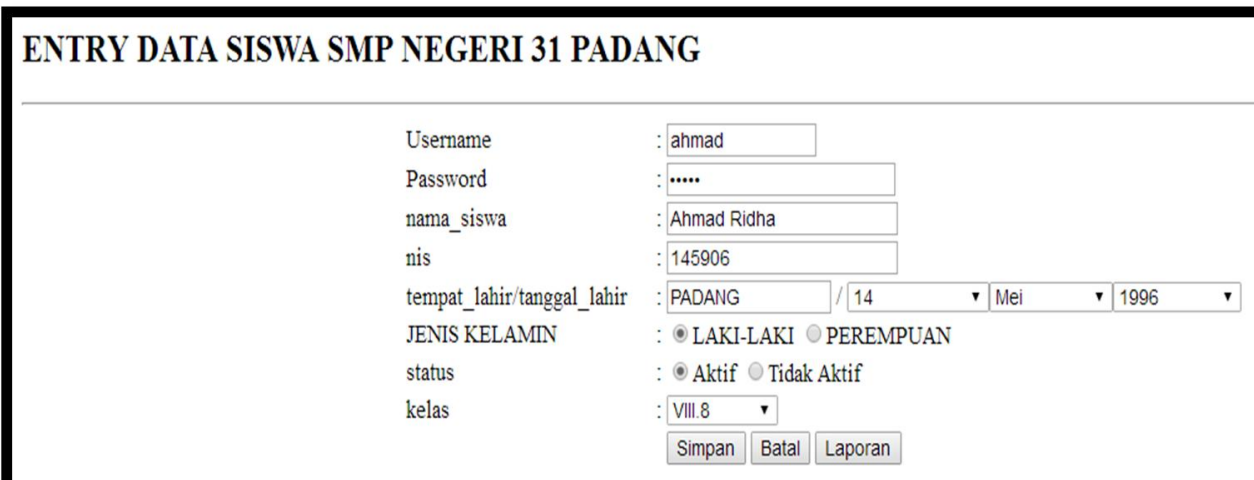

Gambar 13. Tampilan Input Data siswa

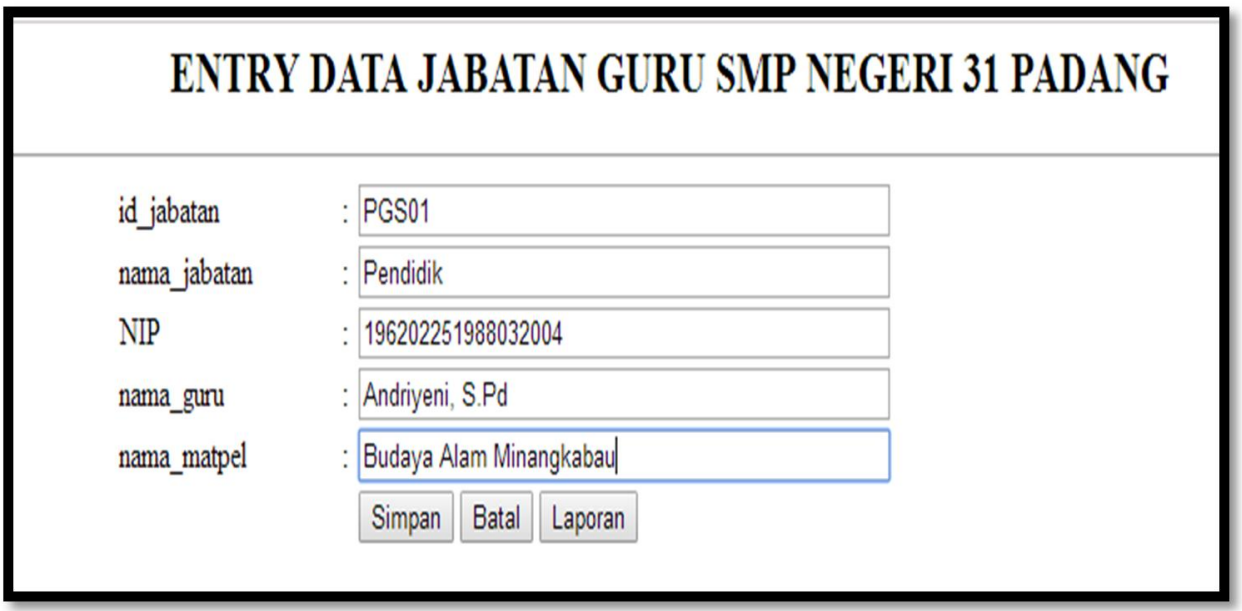

Gambar 14. Tampilan Input Jabatan

$\overline{\text { Samosir, et al., [Perancangan Sistem Informasi Pengolahan Jadwal Mata Pelajaran Siswa Secara Online Di SMPN }}$ 31 Padang Berbasis Web] 


\section{ENTRY DATA KELAS SVIP NEGERI 31 PADANG}

kode kelas

kelas

jumiah siswa

Tahun_Ajaran

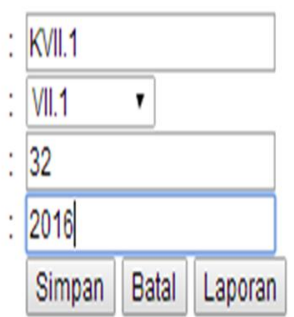

Gambar 15. Tampilan Input Data Kelas

\section{ENTRY DATA MATA PELAJARAY GURU SIIP NEGERI 31 PADAYG}

\begin{tabular}{|c|c|}
\hline kode matpel. & PSD1 ' \\
\hline nama matpel. & BAHASA INDONESA , \\
\hline jam matpel. & $06.45 .07 .50 \mathrm{O}$ \\
\hline $\mathbb{N P}$ & 195605051981032005-195605051981032005 \\
\hline nama guru & 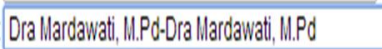 \\
\hline & Simpan Batal Laporan \\
\hline
\end{tabular}

Gambar 16. Tampilan Input Data Mata Pelajaran

ENTRY DATA JADWAL GURU SMP NEGERI 31 PADANG

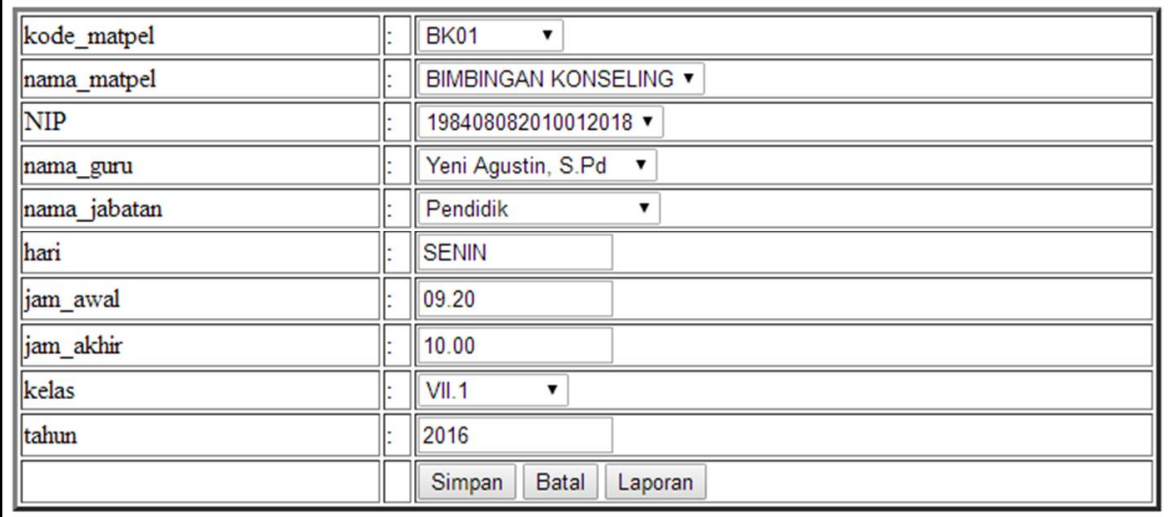

Gambar 17. Tampilan Input Data Jadwal 


\subsection{Form Output/Laporan}

Laporan ini berfungi untuk melihat inputan inputan yang telah di rancangan seperti pada point diatas, adapun laporan-laporannya terdiri dari gambar-gambar berikut ini:

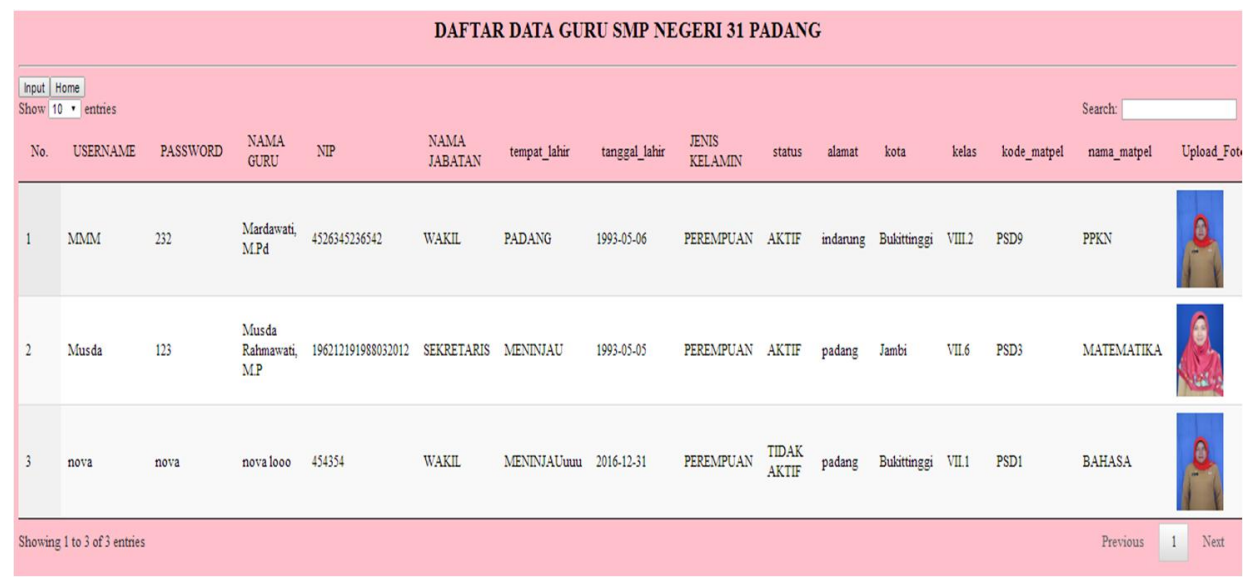

Gambar 18. Tampilan Laporan Data Guru

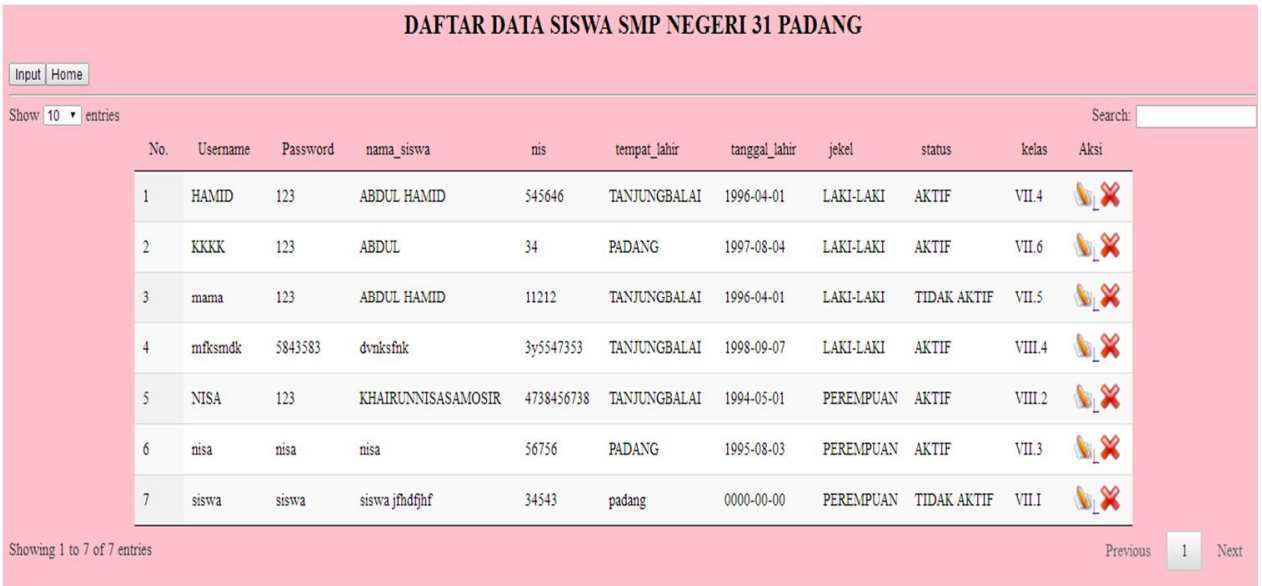

Gambar 19. Tampilan Laporan Data Siswa

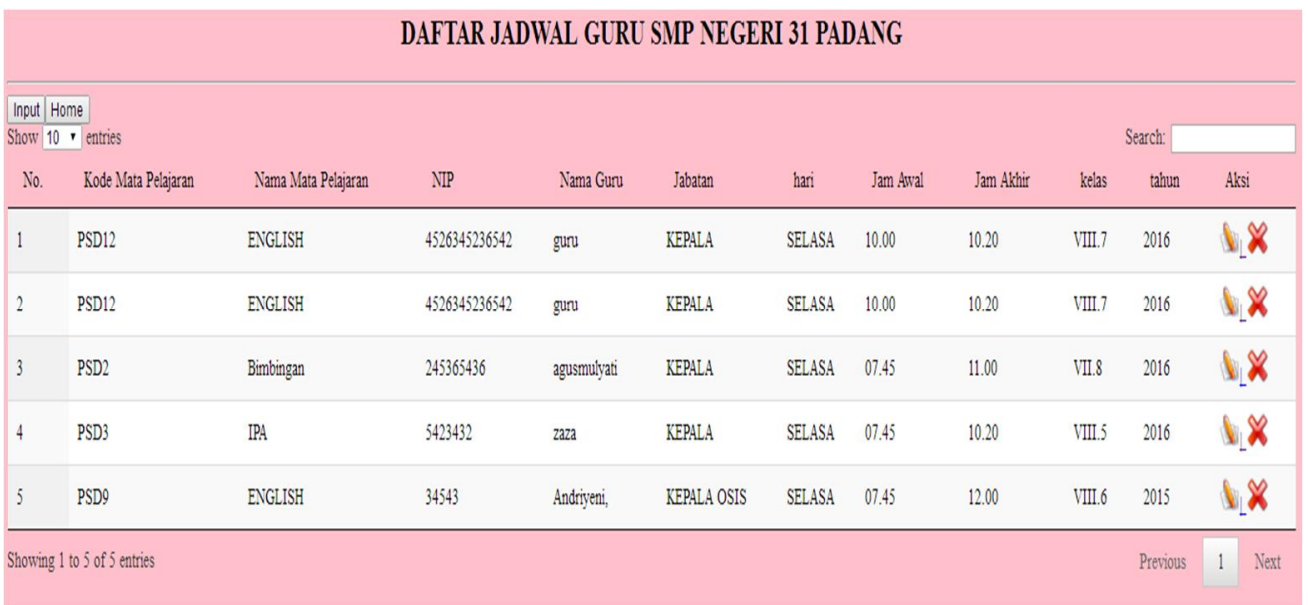

Gambar 20. Tampilan Laporan Jabatan 
Jatisi

ISSN 2407-4322

Vol. 7, No. 3, Desember 2020, Hal. 451-465

E- ISSN 2503-2933

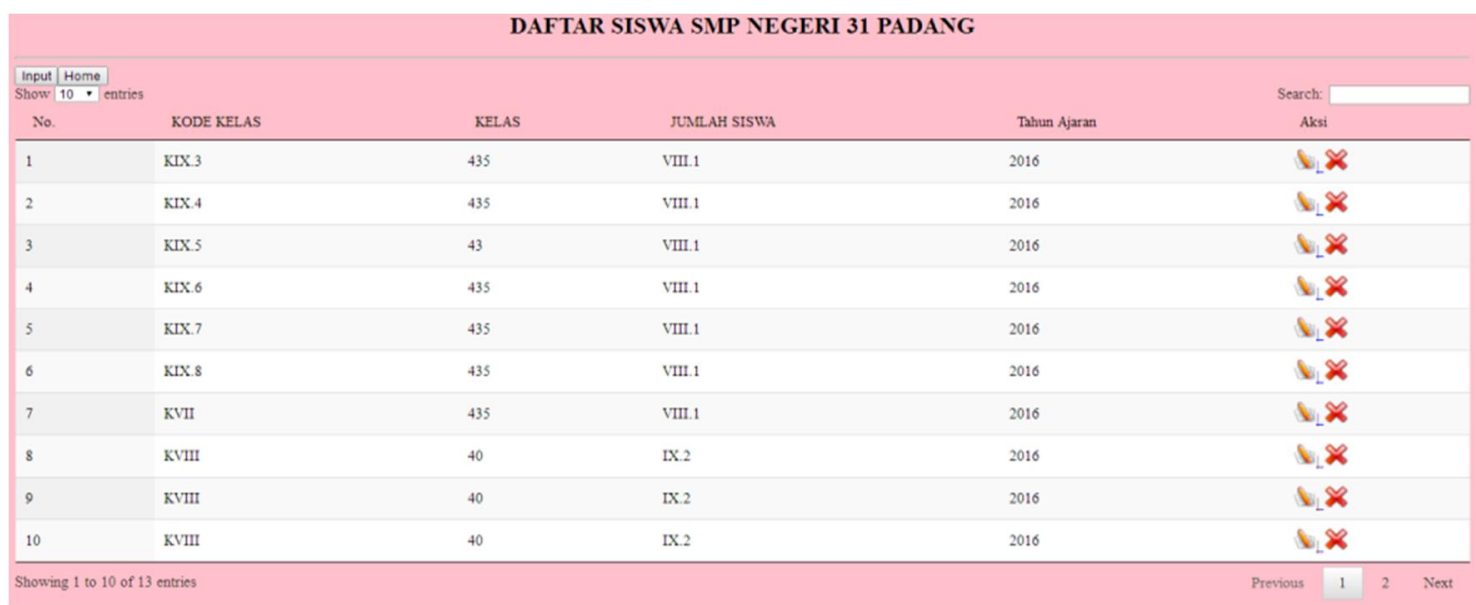

Gambar 21. Tampilan Laporan Kelas

\section{DAFTAR VIATA PELAJARA SSIP NEGERI II PADAIG}

\begin{tabular}{|c|c|c|c|c|c|}
\hline io. lode matpel & namanapal & jam maxpel & NIP & namagnu & Aksi \\
\hline PSDI & $\mathrm{Dra}$ & 06.45 & 1956050519891032005 & $\mathrm{Da}$ & $1 \times$ \\
\hline PSDD12 & BIMAGAN KOISELING & 10.30 & 1961111519990332003 & Nergat, & $x$ \\
\hline PSD2 & BAHASA DIGGRSS & 07.50 & 196212191988032002 & Lissarati, & $1 x$ \\
\hline PSD3 & Verrah & 08.40 & 1057061519880330006 & Verzai, & $1 x$ \\
\hline
\end{tabular}

Gambar 22. Tampilan Laporan Data Mata Pelajaran

\begin{tabular}{|c|c|c|c|c|c|c|c|}
\hline \multicolumn{8}{|c|}{ 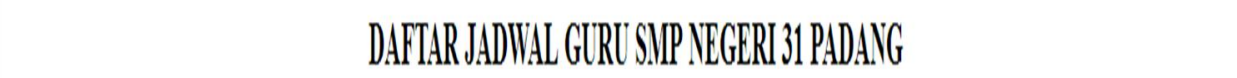 } \\
\hline 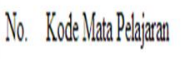 & Nama Vata Peajazan & $\mathbb{I} \mathbb{P}$ & Jama firn & Jadater han & Jam Awal & Iran ablir & kelas tanu Aksi \\
\hline BKO! & BIMBNGAN & 1989090802010012018 & Yein & Peridalli SEDTN & 09.20 & 1000 & vil. 2016 D. \\
\hline 2. PSD? & BHEASA & 1962121919808032002 & Lisarardi, & Peradill: SEVIN & $0,0.50$ & OS:AO & VII. 2016 b. X \\
\hline PSD? & BAHASA & 196012191989803200.2. & Lisarardit, & Perdidil SEETIN & 08.40 & 09.10 & VII.1. 2016 b. \\
\hline
\end{tabular}

Gambar 23. Tampilan Laporan Jadwal Pelajaran 


\section{KESIMPULAN}

Berdasarkan hasil yang didapat dari pembahasan perancangan sistem informasi pengolahan jadwal mata pelajaran siswa secara online, maka dapat diambil beberapa kesimpulan bahwa Aplikasi berbasis Website ini dapat memudahkan siswa untuk melihat jadwal pelajaran karena selama ini siswa hanya mencatat jadwal yang telah diberikan oleh guru. Kemudian jadwal pelajaran siswa secara online yang didukung dengan database mampu menyimpan data jadwal pelajaran sehingga mudah dalam pengolahan berbagai laporan yang dibutuhkan. Siswa dapat mengetahui dengan mudah informasi yang disediakan hanya dengan mengakses Website jadwal pelajaran tersebut.

\section{SARAN}

Pada sistem berbasis Website ini masih membutuhkan beberapa pengembangan untuk menjadikannya lebih sempurna dan hasil yang akurat, berikut adalah saran-saran yang dapat di kembangkan untuk penelitian selanjutnya:

1. Berikan pelatihan bagi guru yang akan mengoperasikan sistem baru, agar sistem dapat berjalan dengan lancar dan mendapatkan hasil sesuai dengan yang diinginkan.

2. Perubahan sistem tidak dilakukan secara mendadak, adaptasi sistem lama dengan sistem yang baru hendaklah dilakukan secara bertahap sehingga sistem yang baru akan terasa keunggulannya dan kelebihannya dibandingkan dengan sistem yang sedang berjalan saat ini.

3. Diharapkan administrator adalah orang-orang yang mempunyai tanggungjawab penuh mengenai website ini dan orang yang berhak mengenai data-data yang ada di dalamnya. Agar sistem ini tetap terjaga maka memberi pengamanan seperti password dan antivirus agar terjaga dari serangan penyusup.

\section{UCAPAN TERIMA KASIH}

Penulis mengucapkan terima kasih kepada semua unit yang telah memberi dukungan baik pemikiran, data dan financial terhadap penelitian ini.

\section{DAFTAR PUSTAKA}

[1] M. A. AS and N. A. Septiani, 2016, "Perancangan Sistem Informasi Akademik Menggunakan Metode Waterfall Studi Kasus: Madrasahaliyah Al-Mansyuriyah Kanza Mekarjaya Tangerang," J. TECHNO Nusa Mandiri, Vol. 13, No. 2, pp. 80-88.

[2] A. Wicaksono, F. Antika, T. A. Wardana, and N. A. Nurfita, 2019, "Perancangan Sistem Informasi Penjadwalan Pelajaran," No. November, pp. 36-44.

[3] M. A. Gerebtzoff, 1966, "Détection Histochimique D’isoenzymes De La Lactate Deshydrogénase Dans De Le Nerf Et Le Ganglion Spinal.," C. R. Seances Soc. Biol. Fil., Vol. 160, No. 6, pp. 1323-1325.

[4] F. Ayu and W. Sholeha, 2019, "Rancang Bangun Sistem Informasi Penjadwalan Mata Pelajaran Berbasis Web pada Smart Center Pekanbaru," Intra-Tech, Vol. 3, No. 1, pp. $38-48$.

Samosir, et al., [Perancangan Sistem Informasi Pengolahan Jadwal Mata Pelajaran Siswa Secara Online Di SMPN 31 Padang Berbasis Web] 
[5] D. Darmansah and Z. Suhendro, 2020, "Sistem Informasi Sekolah pada SD Negeri 21 Sungai Geringging Kabupaten Padang Pariaman Berbasis Web," MATRIK J. Manajemen, Tek. Inform. dan Rekayasa Komput., Vol. 19, No. 2, pp. 235-245, doi: 10.30812/matrik.v19i2.639.

[6] A. Herliana and P. M. Rasyid, 2016, "Sistem Informasi Monitoring Pengembangan Software pada Tahap," J. Inform., No. 1, pp. 41-50.

[7] Hanif AL Fatta, 2017, Analisis dan Perancangan Sistem Informasi, Andi Offset, Yogyakarta.

[8] D. Nataniel and H. R. Hatta, 2009, "Perancangan Sistem Informasi Terpadu Pemerintah Daerah Kabupaten Paser," Vol. 4, No. 1, pp. 47-54.

[9] U. Hasanah, 2013, "Sistem Informasi Penjualan on_Line pada Toko Kreatif Suncom Pacitan," IJNS-Indonesian J. Netw. Secur., Vol. 2, p. 4, [Online]. Available: http://ijns.org.

[10] Rosa, 2013, Rekayasa Perangkat Lunak Terstruktur dan Berorientasi Objek, Informatika, Bandung.

[11] A. Agung, H. M. Maulana, D. C. Andini, and F. Nadziroh, 2018, "Sistem Peminjaman Ruangan Online (Spro) Dengan Metode UML," Jurnal Teknol. dan Terap. Bisnis, Vol. 1, No. 1, pp. 1-8, doi: https://doi.org/10.0301/jttb.v1i1.35. 